\title{
Risk assessment of horizontal transport system in a copper mine
}

\author{
Anna BURDUK ${ }^{1 *}$, Dorota WIĘCEK ${ }^{2}$, Vladimír TLACH ${ }^{3}$, Zuzana SÁGOVÁ \\ and Joanna KOCHAŃSKA ${ }^{1}$
}

\author{
Authors' affiliations and addresses: \\ ${ }^{1}$ Wroclaw University of Science and Technology, \\ 27 Wybrzeże Wyspiańskiego st., 50-370 \\ Wrocław, Poland \\ e-mail: anna.burduk@pwr.edu.pl, \\ e-mail: joanna.kochanska@pwr.edu.pl \\ ${ }^{2}$ University of Bielsko-Biała, 2 Willowa st., 43- \\ 309 Bielsko-Biała, Poland \\ e-mail: dwiecek@ath.bielsko.pl \\ ${ }^{3}$ University of Žilina, Univerzitná 1, 01026 \\ Žilina, Slovak Republic \\ e-mail: vladimir.tlach@fstroj.uniza.sk, \\ e-mail: zuzana.sagova@fstroj.uniza.sk

\section{*Correspondence:} \\ Anna Burduk, Wroclaw University of Science \\ and Technology, 27 Wybrzeże Wyspiańskiego st., \\ 50-370 Wrocław, Poland \\ tel.: +48713203710 \\ e-mail: anna.burduk@pwr.edu.pl
}

How to cite this article:

Burduk, A., Więcek, D., Tlach, V., Ságová, Z. and Kochańska, J. (2021). Risk assessment of horizontal transport system in a copper mine. Acta Montanistica Slovaca, Volume 26 (2), 303314.

DOI:

https://doi.org/10.46544/AMS.v26i2.09

\begin{abstract}
The risk assessment determines threats that could appear during the execution of production system goals. Thus, manufacturing companies need to evaluate and react to the risk as well as it is possible. Due to the complexity and variable character of the mining system, as well as different types of parameters obtained at subsequent stages of the horizontal transport process, the risk was assessed according to various methods. Three stages were distinguished in the horizontal transport system of copper ore studied in the paper: tyre haulage of the shot copper ore to the transfer point, the so-called grate, transferring the output to belt conveyors and crushing solid rock into smaller pieces; transport on belt conveyors. Risk factors have been characterized for each stage. To assess the risk of the loading and haulage processes, an ANN model was built to predict the amount of ore extracted. A general linear neural network model was also built to confirm the results of the correlation analysis. One of the methods recommended for risk assessment in manufacturing companies is the Failure Mode and Effects Analysis (FMEA), which allows for calculating the risk and prioritizing it. The FMEA method allows identifying only these elements of the production system that are the most sensitive to the impact of risk factors. For the next stages of the horizontal transport process, the risk was assessed according to the FMEA method. The risk levels at each stage were different. Production systems are composed of many elements that create the reliability structure of this system. Unfortunately, the FMEA method does not allow for analyzing the reliability structure of the production system. Therefore, the new idea presented in this paper is a method of total risk assessment of the horizontal transport system of copper ore, which does take its reliability structure into account. The currently used methods of risk analysis and assessment do not take into consideration the reliability structure of the production system. The proposed method can be applied for risk assessment in other production systems characterized by a diversified structure.
\end{abstract}

\section{Keywords}

risk assessment, horizontal transport system, FMEA analysis, ANN model, stability of the production system. 


\section{Introduction}

The mining system significantly differs from other production systems, even though it is subject to the same economic laws and to the market pressure of productivity and efficiency improvement (Bošnjak \& Zrnić, 2012; Chaulya \& Prasad, 2016; Pihnastyi \& Khodusov, 2020; Więcek et al., 2019). It could be said that most production systems have stable and predictable environments in that processes are standardized, and material flow takes place in a production hall with a properly designed layout (Chlebus et al., 2015). However, the mining production environment is a natural rock mass, highly variable, unstable and often dangerous due to the threats of rock bumps, fires, flooding and other risks (Pačaiová et al., 2021; Sentyakov et al., 2020). In addition, mines often comprise areas of hundreds of square kilometres, and work is carried out in various places and at various depths (Bajda et al., 2019; Bardzinski et al., 202; Helman, 2012; Kirjanów-Błażej et al., 2019; Procházka, 2014; Turisová et al., 2021; Sharan, 2007). Therefore, analysis of the economic productivity problems can lead to erroneous decisions and actions if the specificity of the mining environment is not taken into account.

Stability of the production system means its ability to get back to equilibrium after disturbances caused by the occurrence of the risk factors cease. With regard to the management of production systems, stability of the production system means its ability to execute the tasks for which it was built (Bubnicki, 2013; Burduk \& Chlebus, 2009; Rosienkiewicz, 2012; Wirth et al., 2016). Values of the parameters required for the correct operation of the system are analyzed with regard to reaching the results assumed in the model that, in the case of production processes, is generally the production schedule (Mahmood, 2008). The specificity of today's production systems, especially their complexity, makes it possible to treat them as operating systems and then reliability is one of their features measured by the realization degree of the scheduled indices, parameters and characteristics. On the other hand, production systems must operate in an environment that continuously affects the system and causes its disturbances. As a result, reliability in real conditions is of a random nature (Burduk \& Chlebus, 2009; Sankar \& Prabhu, 2001). Figure 1 shows the variability of any parameter $P\left(t_{i}\right)$ caused by action of the risk factors $r_{i}$.

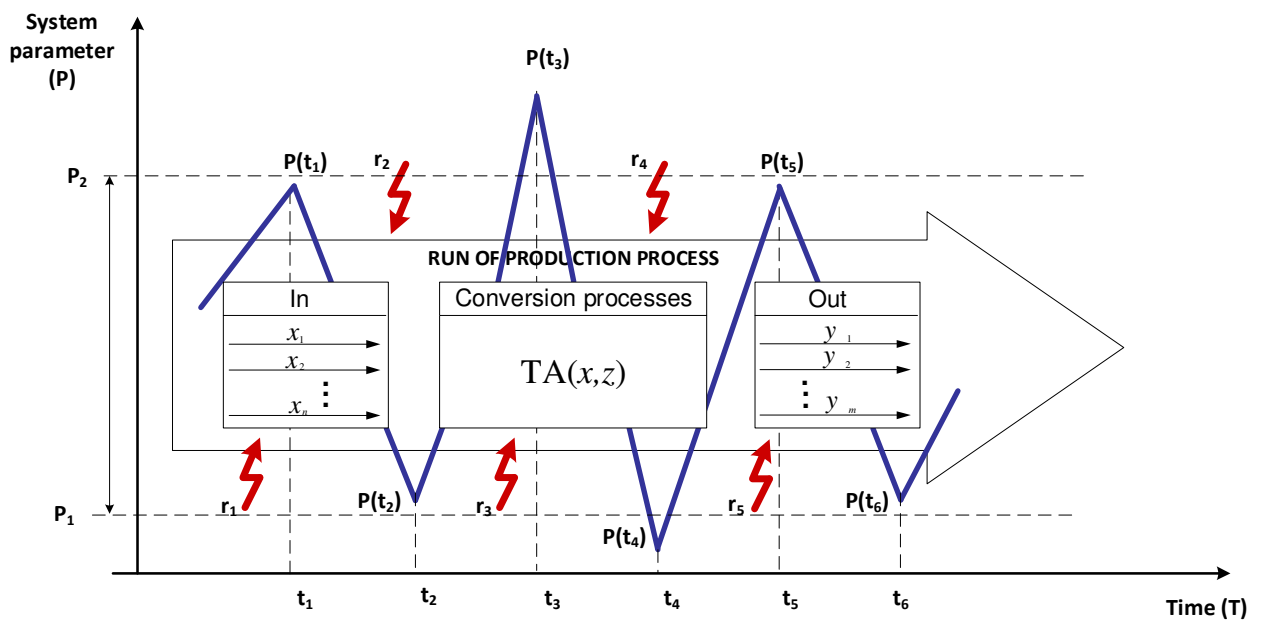

Fig. 1. Variability of the parameter $P\left(t_{i}\right)$ caused by the action of disturbing factors $\left(r_{i}\right)$ on the production system (Wieccek et al., 2019)

If the $P\left(t_{i}\right)$ value at the moment $t_{i}$ is included within the fixed range $P_{1} \leq P\left(t_{i}\right) \leq P_{2}$, this is evidence of the correct course of the process. Otherwise, corrective actions should be taken up.

The ideal solution is a self-responsive production system. Such a system consists of units operating independently based on a high degree of Artificial Intelligence, achieving an absolute degree of automation also in terms of real-time response to system interference. Currently, in real production systems, something like this is a utopia, so automation of decision-making processes is confined to the use of Artificial Intelligence tools in selected areas of the production system (Kuric et al., 2018; Pavlenko et al., 2020; Pecháč \& Sága et al., 2017; Tlach et al., 2017; Zajačko et al., 2018).

The paper is aimed at assessment of the risk of the horizontal transport system of copper ore from the selected extraction field. The risk will be understood as the probability of failure to achieve the goal posed to the system. The analyzed transport system is composed of 3 stages: tyre haulage, crushing rocks and transferring them to a belt conveyor, and horizontal transport with belt conveyors. With regard to the different specificity of individual elements of the system and different parameters acquired by the mine (Koman \& Laska, 2014), a neural network will be built to assess the risk of the tyre haulage, but the risks of the other transport elements will be assessed by the FMEA analysis. At the last stage, the risk for the whole transport system will be determined on the grounds of its reliability structure. 


\section{Material and Methods}

\section{Risk in production systems with series reliability structure}

The term "reliability engineering" is often compared with the system ability to survive. Reliability can be written as the reliability function $N_{(t)}$ that determines the probability of the system operation in a determined time interval and is characterized by the following features (Jansons \& Jurenoks, 2012; Zhang \& Chu, 2011):

- $N_{(0)}=1-$ beginning of the time interval acting correctly,

- $\quad N_{(\infty)}=0$ - infinitely increasing time; means some stoppage of the system.

Therefore, the reliability function decreases in the range from zero to infinity. If the variable $Z_{(t)}$ is accepted as unreliability, it can be concluded that the failure probability is given by the formula (Bowles \& Peláez, 1995):

$$
Z_{(t)}+N_{(t)}=1
$$

The general reliability theory can be transferred to the ground of production systems by treating the unreliability $Z$ - opposite to reliability - as the synonym of risk $R$ (Burduk \& Chlebus, 2009):

$$
R_{(t)}=Z_{(t)}
$$

Such an interpreted risk (unreliability) of the system (e.g. production system) means that it is probable that the system will not fulfil the functions for what it was designed or will be designed or will result in the probability of losses occurring in this system. For such an interpretation, the equation will assume the form:

$$
R_{(t)}+N_{(t)}=1
$$

From the viewpoint of reliability engineering, an object can be treated as an element (distinguished from the system) or as a system (a set of co-operating elements). Individual elements in the system can be linked with each other and can have the reliability structure of series, parallel or series-parallel type.

The system has a series structure if the operation of all the elements is required for its operation. This means that the system works correctly if all its elements also work correctly. Therefore, if any element is damaged, the whole system becomes damaged as well (Tao \& Tam, 2012; Tillman et al., 1977).

In this type of system, the reliability of a system is the product of the reliabilities of its objects, so it decreases with the increasing number of objects in the system. Reliability of the system $N_{s}$ with series structure is given by the formula:

$$
N_{s}=N_{1} \cdot N_{2} \cdot \ldots \cdot N_{n}
$$

where $N_{1}, N_{2}, N_{n}$ are reliabilities of individual elements of the system.

According to the formula (3) and (4), total risk $R_{c}$ of this system will be:

$$
R_{C}=1-\left[\left(1-R_{1}\right) \cdot\left(1-R_{2}\right) \cdot \ldots \cdot\left(1-R_{n}\right)\right],
$$

where $R_{1}, R_{2}, R_{n}$ are risks occurring in individual elements of the system.

The series structure is the most common type of structure in production systems and processes ((Burduk \& Chlebus, 2009). For example, damage of one machine in a manufacturing process results in incorrect functioning or stoppage of the whole production system.

\section{Risk assessment with the use of the FMEA method}

The Failure Mode and Effect Analysis (FMEA) is one of the methods to determine the causes and effects of failures of products or processes and next to determine the corrective actions. The method is a structured approach that starts from identifying potential failures at one level or stage of the process and examining their influence on the subsequent level or stage. All complex mechanical systems are composed of a few sub-systems that can be further divided to the level of a component (Wang, 1995). As a formal method, FMEA was first suggested by NASA in 1963. In the 1990s, it was adopted within the ISO 9000 standard, particularly QS-9000 designed for the automotive industry. Since that time, it has been widely used as a tool for safety and reliability analysis of products and processes in many industries, especially in the aircraft, nuclear and automotive industries (Ebeling, 2000; Gilchrist, 1993; O'Connor \& Kleyner, 2012). 
In order to assess the risk, it is necessary to acquire the data for measurements of sizes and probabilities of the occurrences that can cause losses in the business activity. The measurement should include (Ebeling, 2000; Gilchrist, 1993; O'Connor \& Kleyner, 2012; Petrović et al., 2014; Sankar \& Prabhu, 2001):

- $\quad$ size of the risk understood as the amount of the probable and the maximum loss,

- probability of failure to achieve the goal posed to the system,

- probability of failure to meet the requirements towards the product.

To assess the risk of a production process using the FMEA method, one should first specify operations of the process, then identify failures in the process, determine results caused by the occurrence of these failures and identify their possible causes. The next step in the analysis is giving numerical values to the following parameters:

- $(Z)$ - the threat level determining the size of the effects resulting from the occurrence of the failure during the manufacturing process and the product use,

- $(P)$ - the probability of the occurrence of the failure,

- $(T)$ - detectability being the probability that the potential failure or its cause will appear later.

The usually applied score scale for determining values of the parameters $(Z),(P)$ and $(T)$, as well as their dependence from the estimated risk, is shown in Figure 2.

\begin{tabular}{|c|c|c|c|c|c|c|c|c|c|c|c|}
\hline \multicolumn{2}{|l|}{ Index } & 1 & 2 & 3 & 4 & 5 & 6 & 7 & 8 & 9 & 10 \\
\hline Threat level & $\mathbf{Z}$ & & & & & im & rist & & & & \\
\hline Probabillity & $\mathbf{P}$ & & & & & ima & risk & & & & \\
\hline Detectabillity & $\mathrm{T}$ & & & & & 1 & risk & & & & \\
\hline
\end{tabular}

Fig. 2. Scale and dependence of parameters in relation to the size of the risk

The size of the risk, the so-called Risk Priority Number $(R P N)$, is calculated from the formula (Bowles \& Peláez, 1995; Ebeling, 2000; Gilchrist, 1993; O'Connor \& Kleyner, 2012; Sankar \& Prabhu, 2001):

$$
R P N=(Z) \cdot(P) \cdot(T)
$$

Figure 3 shows four areas illustrating losses caused by the occurrence of risk factors and risk areas in relation to the values of the parameters $(Z),(P)$ and $(T)$.

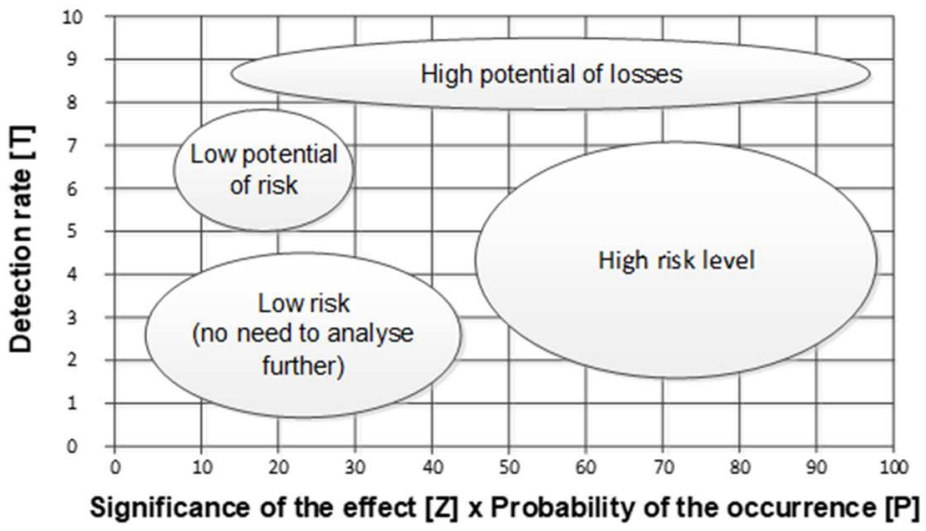

Fig. 3. Risk areas in relation to values of the parameters $(Z),(P)$ and $(T)$

Calculation of this $R P N$ value gives a view of the estimated risk and serves as a reference point for the subsequent measures that should be undertaken to minimize the risk. The $R P N$ value ranges between 1 and 1000 . The high $R P N$ value corresponds to the high risk in the process. All the possible failures should be arranged according to increasing RPN value, and attempts to repair the failures are taken in the same order.

\section{Characteristics and risk assessment of the analyzed horizontal transport system}

The purpose of the horizontal transport system in a mine is to transport the output from extraction fields to the drawing shaft, from where copper ore is delivered to the ore dressing plants. In the analyzed mine, the extraction process is carried out in the room and pillar system, which means that the field is prepared for extraction 
by making galleries and dog headings. Extraction occurs in many places at the same time, on many extraction fields in their various parts. The place where the extraction process is carried out is called a face. Winning of rocks is carried out by the blasting technique and consists of mechanical drilling of blast holes. Next, the drilled blastholes are loaded with an explosive and fired with an electric detonator. The horizontal transport system examined in this paper is shown in Fig. 4.

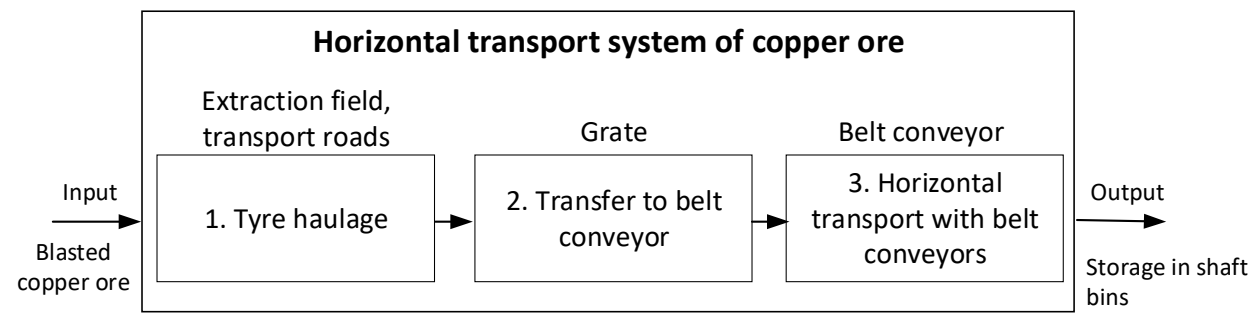

Fig. 4. Stages of the horizontal transport system of copper ore

The first examined stage of the copper ore transport system is tyre haulage of the shot copper ore to the transfer point, the so-called grate. This transport is carried out by means of haul trucks (HT) loaded by the loaders working on the extraction field. The mining loaders transfer the winning from the faces to the haul truck provided directly to the loading point. The winning is next transported by the haul trucks to damping points (grates).

The second stage is aimed at transferring the winning to belt conveyors and crushing solid rocks into smaller pieces. At the transfer point, the winning from the haul truck is supplied to the grate with 20 to 24 meshes, size $450 \mathrm{~mm}$ x $450 \mathrm{~mm}$. Here, the ore is preliminarily crushed by means of a hydraulic hammer. The crushed ore is fed by trolley conveyors (feeders) on a belt conveyor located directly beneath the grate.

The third stage takes place on belt conveyors. The system of belt conveyors transports the ore to shaft-bins located in the vicinity of the output shafts.

\section{Risk assessment at the stage of loading and haulage}

The loading and haulage process is aimed at transferring ore from the face to the grate being the transfer point, i.e. the place where ore is disintegrated and transferred on a belt conveyor. Analysis of the data delivered by the mine showed that the main factors disturbing the loading and haulage process are, apart from malfunctions of mining machines, variable environmental conditions. These conditions make the time required for haulage of the winning and return of the haul trucks from the grate to the face highly variable. The loading and haulage time is mostly dependent on the following factors (Burduk et al., 2020):

1. number of haul trucks (HT) and mine loaders (ML),

2. condition and length of the supply road from the face to the grate. This condition is influenced by the kind of rocks in the floor, inclination and water accumulation. After some time, heavy road transport creates wheel tracks, and the thickness of the mud layer reaches even $80 \mathrm{~cm}$.

3. loading time of haul trucks by mine loaders. This parameter mostly depends on the distance that must be covered by the loader from the place where the fired ore is dumped to the parking place of the haul truck. This distance can amount from 3 to $30 \mathrm{~m}$.

In order to assess the risk of the loading and haulage process, it was decided to build an artificial neural network (ANN), a single-layer perceptron type. The parameters mentioned above were selected as explanatory variables at building the ANN model, which is shown in Figure 5.

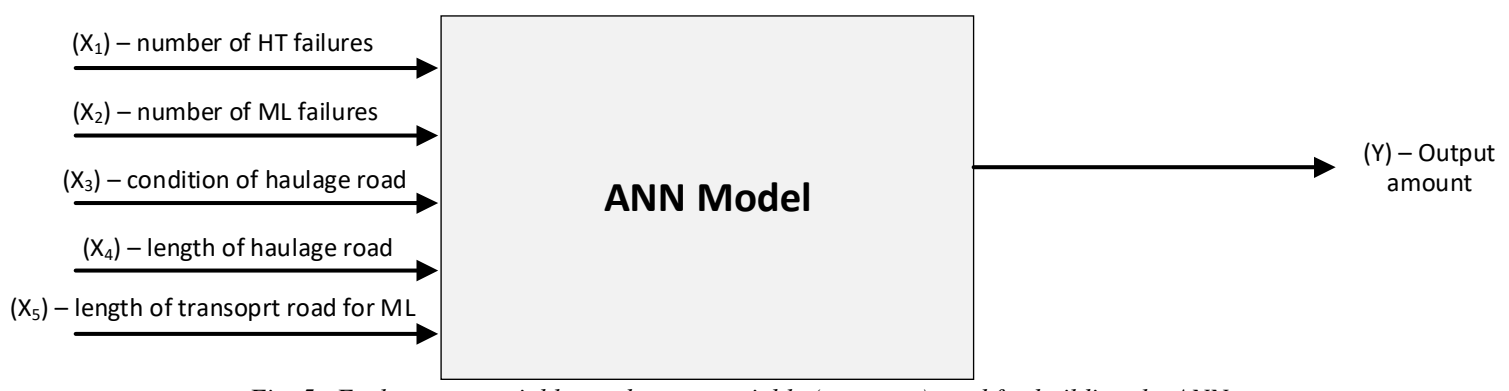

Fig. 5. Explanatory variables and target variable (response) used for building the ANN

The amount of the winning in the production schedule was fixed at 330 tons of copper ore per one production shift. The experiment was carried out in the SAS Enterprise Miner 6.2 environment. The first step was examining the correlation between the explanatory variables and the response variable. The results, including the correlation value, are shown in Table 1. 
Tab. 1. Correlation between variables

\begin{tabular}{c|c}
\hline Explanatory attribute (variable) & Correlation value \\
\hline$\left(X_{1}\right)=$ number of HT failures & 0.2009 \\
\hline$\left(X_{2}\right)=$ number of ML failures & -0.07535 \\
\hline$\left(X_{3}\right)=$ condition of haulage road & -0.32767 \\
\hline$\left(X_{4}\right)=$ haulage distance & 0.28976 \\
\hline$\left(X_{5}\right)=$ distance for ML & 0.43691 \\
\hline
\end{tabular}

The obtained results indicate that it is not reasonable to use the linear regression method for the analyzed problem (absolute correlation values are below 0.5). Therefore, it is reasonable to use neural networks to build non-linear regression models.

\section{Results and Discussion}

\section{Risk assessment for the loading and haulage processes with the use of ANN}

A unidirectional neural perceptron-type network was built in order to foresee amounts of the extracted ore in the loading and haulage process at the assumed input values, changing the numbers of neurons in the hidden layer. A neural network type general linear model was also built to confirm the results of the correlation analysis. The observation results and time measurements in the loading and haulage process served as a set of explanatory data. In total, 218 measurements were taken during 21 days on 3 working shifts. The measurements were taken by shift foremen on specially prepared forms. Figure 6 shows a screenshot from the SAS Enterprise Miner 6.2 program with the built models.

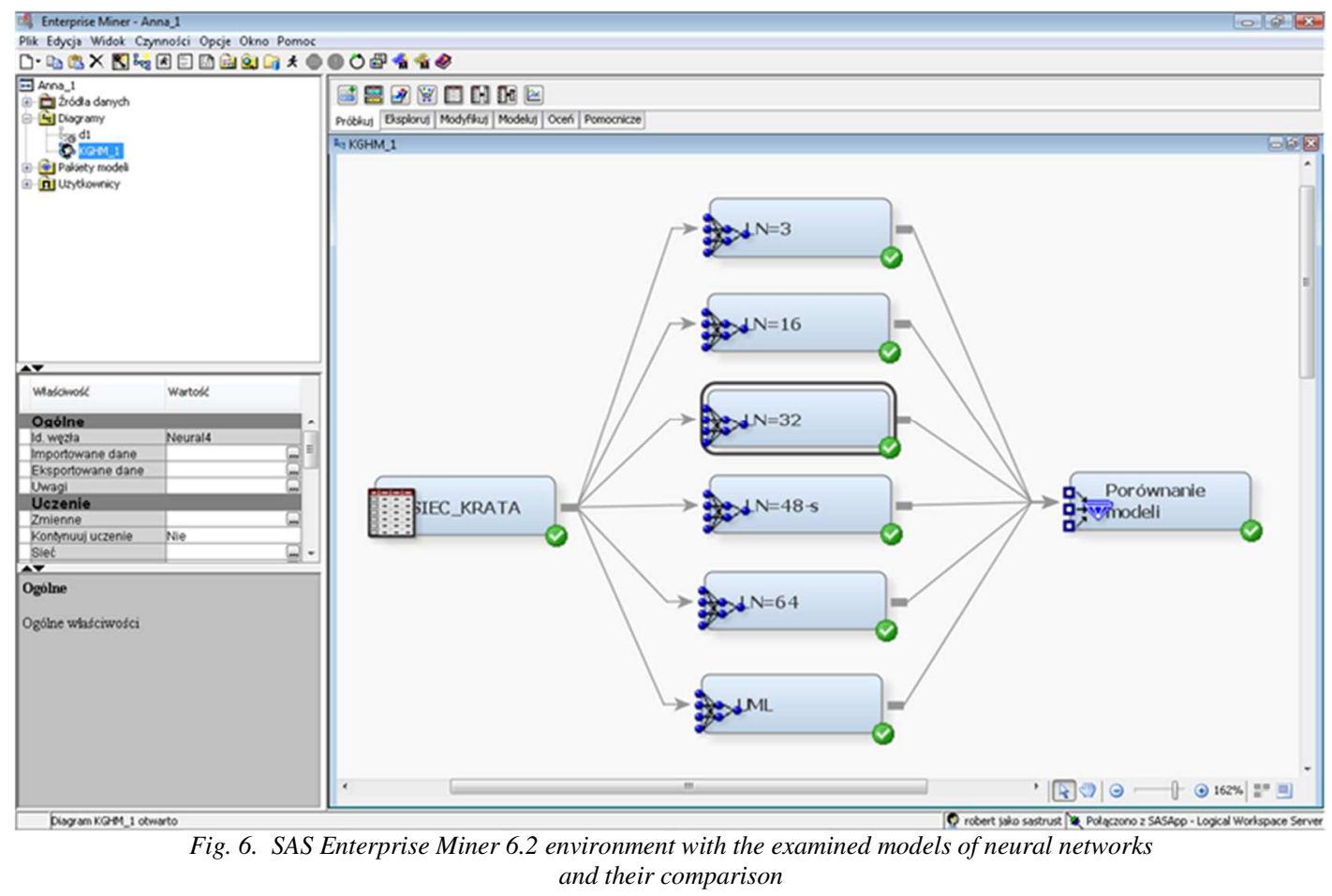

Several experiments were carried out for various numbers of explanatory variables for the constructed models of neural networks. The experiments were aimed at finding the combination of the explanatory variables that would best determine the output rate. When building the models, various numbers of explanatory variables were considered. Their selection was dictated by the previous experiments, so it depended on values of the absolute correlation, see Table 1. In Experiment No. 1, all the input attributes were used. In Experiment No. 2, the attribute " $\left(\mathrm{X}_{1}\right)=$ number of HT failures" was resigned (the lowest absolute correlation value), and in Experiment No. 3, additionally the attribute " $\left(\mathrm{X}_{2}\right)=$ number of ML failures" was resigned (the subsequent lowest absolute correlation value). Low correlation value can result from the fact that the mine division managers, taking into account possible failures, send an excessive number of machines to work. The obtained results are shown in Table 2, where the values present the network selection criterion, which is the mean square error. The results concern analysis of the input data set that was also used for the network learning process. 
Tab. 2. Experimental results from the neural network

\begin{tabular}{c|c|c|c}
\hline \multirow{2}{*}{ Neural network model } & \multicolumn{3}{|c}{ Mean square error } \\
\cline { 2 - 4 } & Experiment No. 1 & Experiment No. 2 & Experiment No. 3 \\
\hline MLP - nbrHID =3 & 1228.59 & 1643.71 & 2375.39 \\
\hline MLP - nbrHID =16 & 1072.43 & 1369.98 & 1851.50 \\
\hline MLP - nbrHID =32 & 427.08 & 866.69 & 1033.93 \\
\hline MLP - nbrHID =48 & 327.15 & 764.22 & 999.25 \\
\hline MLP - nbrHID =64 & 348.80 & 772.59 & 2537.86 \\
\hline GLM & 2440.74 & 2450.18 &
\end{tabular}

MLP = the multilayer perceptron-type network nbrHID $=$ number of neurons in the hidden layer GLM = generalized linear model

Analysis of the results confirms that linear models are not suitable for this problem. For each experiment, the worst results (with the highest mean square error) were obtained for the generalized linear model (GLM) network. The best results were obtained for the multilayer perceptron network with 48 neurons in Experiment No. 1. This model of the neural network was used for further experiments.

In order to determine the risk for the loading and haulage process, test data were prepared, and the "score" node of the environment SAS Enterprise Miner 6.2 was used. The test data included different variants of the input attributes (explanatory variables). Exemplary test data together with the expected output values are presented in Table 3.

Tab. 3. Collected test data for different values of explanatory variables in risk assessment with the use of ANN

\begin{tabular}{|c|c|c|c|c|c|c|c|}
\hline & $\begin{array}{c}X_{1} \text { - number } \\
\text { of HT failures }\end{array}$ & $\begin{array}{l}X_{2} \text { - number } \\
\text { of ML failures }\end{array}$ & $\begin{array}{l}X_{3}-\text { road } \\
\text { condition }\end{array}$ & $\begin{array}{c}X_{4} \text { - haulage } \\
\text { distance } \\
{[\mathrm{m}]}\end{array}$ & $\begin{array}{c}X_{5} \text { - distance } \\
\text { for } \mathrm{ML} \\
{[\mathrm{m}]}\end{array}$ & $\begin{array}{l}\text { Expected output } \\
{[\mathrm{t}]}\end{array}$ & $\begin{array}{c}\text { Size of risk } \\
R\end{array}$ \\
\hline \multirow{4}{*}{ 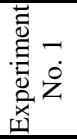 } & 1 & 1 & 3 & 750 & 15 & 338 & 0 \\
\hline & 2 & 1 & 3 & 750 & 15 & 310 & 0.06 \\
\hline & 3 & 1 & 3 & 750 & 15 & 261 & 0.21 \\
\hline & 4 & 1 & 3 & 750 & 15 & 196 & 0.41 \\
\hline \multirow{4}{*}{ 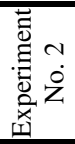 } & 2 & 2 & 2 & 800 & 20 & 297 & 0.1 \\
\hline & 2 & 3 & 2 & 800 & 20 & 209 & 0.37 \\
\hline & 2 & 4 & 2 & 800 & 20 & 154 & 0.53 \\
\hline & 2 & 5 & 2 & 800 & 20 & 78 & 0.76 \\
\hline \multirow{4}{*}{ 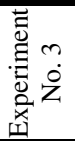 } & 2 & 1 & 1 & 700 & 10 & 348 & 0 \\
\hline & 2 & 1 & 2 & 700 & 10 & 277 & 0.16 \\
\hline & 2 & 1 & 3 & 700 & 10 & 233 & 0.29 \\
\hline & 2 & 1 & 4 & 700 & 10 & 183 & 0.44 \\
\hline \multirow{5}{*}{ 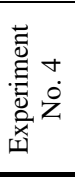 } & 1 & 2 & 4 & 700 & 5 & 339 & 0 \\
\hline & 1 & 2 & 4 & 750 & 5 & 336 & 0 \\
\hline & 1 & 2 & 4 & 800 & 5 & 334 & 0 \\
\hline & 1 & 2 & 4 & 850 & 5 & 293 & 0.11 \\
\hline & 1 & 2 & 4 & 900 & 5 & 257 & 0.22 \\
\hline \multirow{4}{*}{ 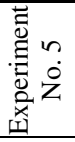 } & 0 & 0 & 1 & 850 & 10 & 323 & 0.02 \\
\hline & 0 & 0 & 1 & 850 & 15 & 302 & 0.08 \\
\hline & 0 & 0 & 1 & 850 & 20 & 196 & 0.40 \\
\hline & 0 & 0 & 1 & 850 & 30 & 178 & 0.46 \\
\hline
\end{tabular}

Results of individual experiments presented in Table 3 show the way how, at various values of input data, the output value from the neural network, i.e. the mine output, will change. On the grounds of the expected output value in the last column, the size of the risk can be calculated from the formula:

$$
R_{\text {stage } 1}=1-\frac{\text { expected output value }}{\text { scheduled output value }}
$$

where the scheduled output value is 330 tons per one production shift.

\section{Risk assessment at the stage of transferring to the belt conveyor}

The next element of the analyzed copper ore horizontal transport system was the so-called "grate", i.e. divisional transfer point to the belt conveyor, equipped with a facility for crushing solid rocks (see Figure 7).

The data about the grate failures, delivered by the mine, covered the period of 26 months and came from the database of the dispatcher of the horizontal transport division. All the information was written in a datasheet in the form of tables containing the designation of the failure, its date, commencement time, duration time, description and classification to failure types. Failures only, which stopped the transport system for a time longer than 2 hours (98 failures), were considered. On the basis of analysis of these failures, an Ishikawa diagram was prepared, presenting the causes of the grate stoppage in a graphic way (Figure 8). 


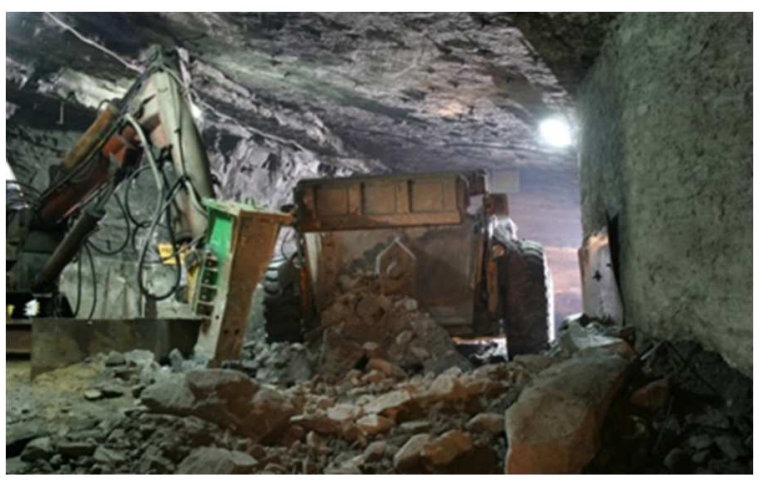

Fig. 7. Unloading the haul truck on the grate

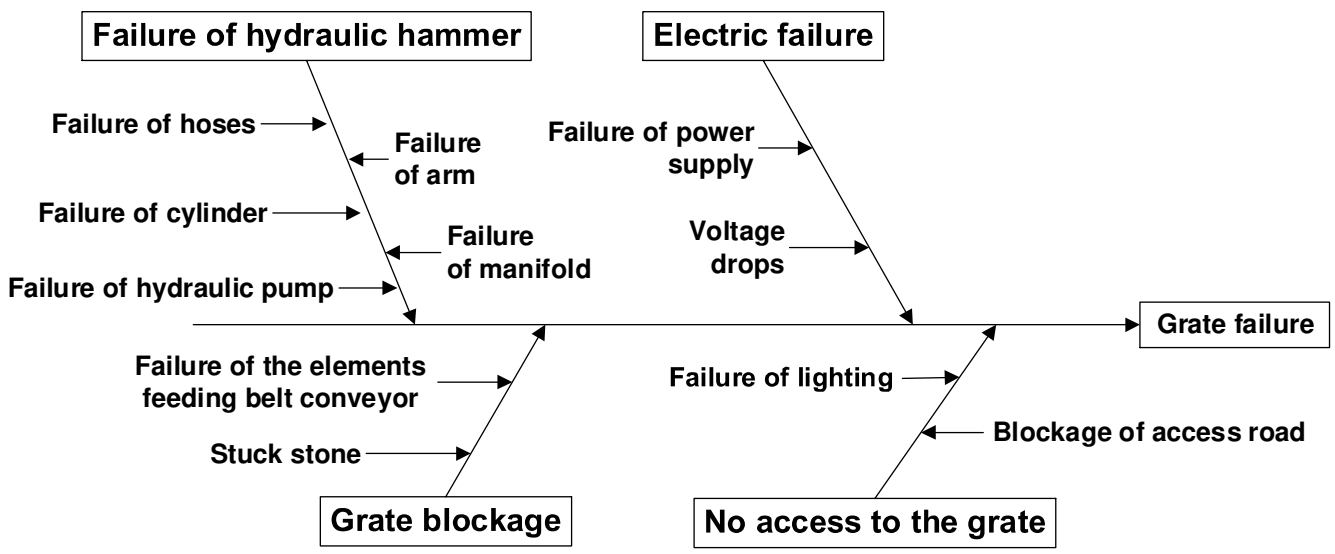

Fig. 8. Basic causes of the grate stoppage - Ishikawa diagram

The Ishikawa diagram presents a list of grouped causes of the problem, but it does not indicate which causes are most important for the production system. Therefore, the method of the Ishikawa diagram, also called a cause and effect diagram, is often combined with other methods, e.g. FMEA, which make it possible to determine the significance of the causes. In Table 4, the failure mode and effects analysis (FMEA) for the transfer point failure is presented.

Tab. 4. FMEA for failures of the transfer point

\begin{tabular}{|c|c|c|c|c|c|}
\hline Designation & Cause of the failure & $\begin{array}{c}(\mathrm{Z}) \\
\text { [points] }\end{array}$ & $\begin{array}{c}(\mathrm{P}) \\
\text { [points] }\end{array}$ & $\begin{array}{c}(\mathrm{T}) \\
\text { [points] }\end{array}$ & $\begin{array}{c}\text { Risk RPN } \\
\text { [points] }\end{array}$ \\
\hline \multirow{5}{*}{$\begin{array}{c}\text { Stoppage } \\
\text { of the hydraulic } \\
\text { hammer }\end{array}$} & Failure of hoses & 7 & 5 & 3 & 90 \\
\hline & Failure of the hydraulic cylinder & 7 & 7 & 5 & 245 \\
\hline & Failure of the hydraulic pump & 7 & 6 & 3 & 126 \\
\hline & Failure of the arm & 7 & 3 & 7 & 147 \\
\hline & Failure of the manifold & 7 & 4 & 4 & 112 \\
\hline \multirow{2}{*}{ Electrical failure } & No power supply & 10 & 7 & 10 & 700 \\
\hline & Voltage drops & 8 & 9 & 4 & 288 \\
\hline \multirow{2}{*}{$\begin{array}{l}\text { Blockage } \\
\text { of the grate }\end{array}$} & Failure of the feeding elements & 9 & 6 & 6 & 324 \\
\hline & Stuck stone & 9 & 5 & 9 & 405 \\
\hline \multirow{2}{*}{$\begin{array}{l}\text { No access } \\
\text { to the grate }\end{array}$} & Failure of lighting & 10 & 7 & 10 & 700 \\
\hline & Blocked access road & 10 & 3 & 10 & 300 \\
\hline
\end{tabular}

To calculate the risk of transferring the ore to the belt conveyor, the failures with $R P N_{i} \geq 200$ were only considered. The risk for this stage was calculated from the formula:

$$
R_{\text {stage } 2}=\frac{\sum R P N_{i}}{\sum R P N_{\max }}=\frac{2962}{11000}=0.27
$$

The determined risk in this way means that the production target, i.e. disintegration and transfer of tons of copper ore delivered during the working shift, will not be reached with the probability of $27 \%$. 


\section{Risk assessment for belt conveyors with use of the FMEA method}

The last element of the horizontal transport system is the transport with belt conveyors. The data on failures of the conveyors, delivered by the mine, covered the last 29 months and the delivered datasheet contained over 3000 records concerning failures. With regard to a large number of failures and their various designations, they were classified into groups related to individual components of the belt conveyor (Figure 9). Like before, only the failures causing a stoppage of the conveyor for at least 2 hours were considered.

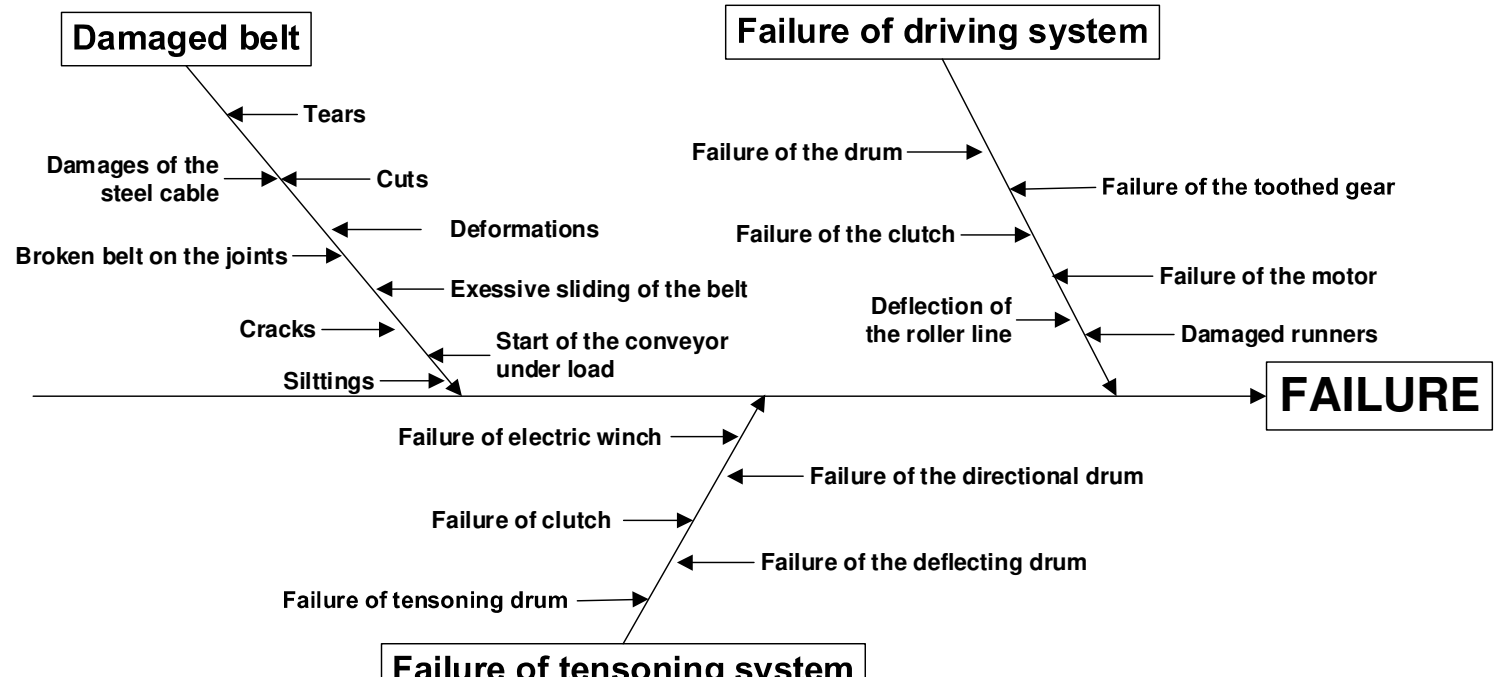

Fig. 9. Basic causes of stoppages of belt conveyors - Ishikawa diagram

In the next step, in order to estimate the risk factors of the conveyor failure, the FMEA analysis was performed (see Table 5)

Tab. 5. FMEA for failures of the belt conveyors

\begin{tabular}{|c|c|c|c|c|c|}
\hline Designation & Cause of the failure & $\begin{array}{c}(\mathrm{Z}) \\
\text { [points] }\end{array}$ & $\begin{array}{c}(\mathrm{P}) \\
\text { [points] }\end{array}$ & $\begin{array}{c}(\mathrm{T}) \\
\text { [points] }\end{array}$ & $\begin{array}{c}\text { Risk RPN } \\
\text { [points] }\end{array}$ \\
\hline \multirow{9}{*}{$\begin{array}{l}\text { Damaged } \\
\text { belt }\end{array}$} & Steel cable damage & 4 & 7 & 3 & 84 \\
\hline & Broken belt on the joints & 10 & 4 & 6 & 240 \\
\hline & Cracks & 8 & 6 & 5 & 240 \\
\hline & Slittings & 6 & 7 & 5 & 210 \\
\hline & Tears & 7 & 4 & 6 & 168 \\
\hline & Cuts & 7 & 6 & 3 & 126 \\
\hline & Deformations & 7 & 6 & 4 & 168 \\
\hline & Excessive sliding of the belt & 5 & 9 & 7 & 315 \\
\hline & Start of the conveyor under load & 4 & 10 & 9 & 360 \\
\hline \multirow{5}{*}{$\begin{array}{l}\text { Failure of the driving } \\
\text { system }\end{array}$} & Failure of the drum & 6 & 6 & 8 & 288 \\
\hline & Failure of the clutch & 5 & 8 & 3 & 120 \\
\hline & Deflection of the roller line & 2 & 6 & 4 & 48 \\
\hline & Failure of the toothed gear & 7 & 8 & 5 & 280 \\
\hline & Failure of the motor & 9 & 7 & 3 & 189 \\
\hline \multirow{5}{*}{$\begin{array}{c}\text { Failure of the tensioning } \\
\text { system }\end{array}$} & Failure of the electric winch & 8 & 6 & 6 & 288 \\
\hline & Failure of the clutch & 8 & 5 & 6 & 240 \\
\hline & Failure of the tensioning drum & 8 & 5 & 5 & 200 \\
\hline & Failure of the directional drum & 7 & 6 & 6 & 252 \\
\hline & Failure of the deflecting drum & 7 & 5 & 6 & 210 \\
\hline
\end{tabular}

Like before, to calculate the risk for this stage, the failures with $R P N_{i} \geq 200$ were only considered. The risk was calculated from the formula:

$$
R_{\text {stage } 3}=\frac{\sum R P N_{i}}{\sum R P N_{\max }}=\frac{3312}{19000}=0.174
$$

The determined risk in this way means that the production target posed to the transport system, i.e. transporting 330 tons of copper ore per shift, will not be reached with the probability of $17.4 \%$.

\section{Risk assessment of the complete horizontal transport system}

The risk calculated using formulas (7), (8) and (9) has different values at three stages of the horizontal transport process of copper ore. To assess the risk for the entire horizontal transport system, it is necessary to 
consider its series reliability structure (Fig. 4) and use the formula for the risk for the systems with series structure (Bubnicki, 2013). Then, the total risk of the analyzed horizontal transport system can be calculated from the formula:

$$
R_{\text {Cst }}=1-\left[\left(1-R_{\text {stage } 1}\right) \cdot\left(1-R_{\text {stage } 2}\right) \cdot\left(1-R_{\text {stage } 3}\right)\right]
$$

where $R_{C s t}$ is the total risk of the horizontal transport system and $R_{\text {stage }}$ are risk values of individual stages of the analyzed process.

The risk for stage 1 (loading and haulage) was assessed using an ANN model that predicted the output volume for various values of explanatory variables. The $\mathrm{R}_{\mathrm{Cst}}$ value was calculated using the result of Experiment No. 1 for 4 failures of haul tracks, equal to 0.41 (Table 3):

$$
\left.R_{C s t}=1-(1-0.41) \cdot(1-0.27) \cdot(1-0.174)\right]=1-[0.59 \cdot 0.73 \cdot 0.826]=1-0.36=0.64 .
$$

The determined risk means that the production target posed to the transport system, i.e. transporting 330 tons of copper ore per shift, will not be reached with the probability of $64 \%$. Such a high risk means that the impact intensity of the factors disturbing the transport system in the analyzed mine is very high.

\section{Conclusions and Future Research}

The complete risk of the transport system of copper ore was assessed using the general reliability theory. Because of the complex and variable nature of an extraction system, as well as different types of parameters at various process stages acquired by the mine, it was necessary to assess the risks of individual process stages using different methods. To that end, the analyzed transport system was divided into 3 stages. Each stage was characterized, and the influencing risk factors were presented. The risk of the loading and haulage stage was assessed by means of the constructed ANN model. At the subsequent two stages - transfer of the winning to the belt conveyor and transport of the winning by belt conveyors - the risk was assessed using the FMEA method. Risk sizes at each stage of the analyzed process were different. In the last step of the suggested method, the total risk of the horizontal transport system of copper ore was calculated using the series reliability structure of the analyzed system. The presented method can be used for risk assessment in other production systems, especially in those with diversified structure.

The determined total risk $\mathrm{R}_{\mathrm{Cst}}$ of the analyzed system is very high, equal to $64 \%$. The response of the mine is building numerous retention tanks and shaft-bins. These containers play the role of safety buffers protecting the supplies to the ore dressing plants (vertical transport through extraction shafts). Nevertheless, such a high-risk level results in losses caused by numerous failures of production resources and influences the financial results of the company. Therefore, it seems necessary to develop actions and programs that, implemented to the production practice, will reduce the size of the risk.

\section{References}

Bajda, M., Błażej, R., \& Jurdziak, L. (2019). Analysis of changes in the length of belt sections and the number of splices in the belt loops on conveyors in an underground mine. Engineering Failure Analysis, 101, 436446. https://doi.org/10.1016/j.engfailanal.2019.04.003

Bowles, J. B., \& Peláez, C. E. (1995). Fuzzy logic prioritization of failures in a system failure mode, effects and criticality analysis. Reliability Engineering \& System Safety, 50(2), 203-213. https://doi.org/10.1016/09518320(95)00068-D

Bošnjak, S. M., \& Zrnić, N. Đ. (2012). Dynamics, failures, redesigning and environmentally friendly technologies in surface mining systems. Archives of Civil and Mechanical Engineering, 12, 348-359. https://doi.org/10.1016/j.acme.2012.06.009

Bardzinski, P., Jurdziak, L., Kawalec, W., \& Krol, R. (2020). Copper ore quality tracking in a belt conveyor system using simulation tools. Natural Resources Research, 29(2), 1031-1040. https://doi.org/10.1007/s11053$\underline{019-09493-6}$

Bubnicki, Z. (2013). Analysis and decision making in uncertain systems. Springer Science \& Business Media. 10.1007/978-1-4471-3760-3

Burduk, A., \& Chlebus, E. (2009). Methods of risk evaluation in manufacturing systems. Archives of Civil and Mechanical Engineering, 9(3), 17-30. https://doi.org/10.1016/S1644-9665(12)60215-5 
Burduk, A., Więcek, D., Zajačko, I., Jurdziak, L., \& Błażej, R. (2020). Analysis and risk assessment of the supply of copper ore in the belt conveyor system in an underground mine. Acta Montanistica Slovaca, 25(2). DOI 10.46544/AMS.v25i2.10

Chaulya, S., \& Prasad, G. M. (2016). Sensing and monitoring technologies for mines and hazardous areas: monitoring and prediction technologies. Elsevier.

Chlebus, E., Helman, J., Olejarczyk, M., \& Rosienkiewicz, M. (2015). A new approach on implementing TPM in a mine-A case study. Archives of Civil and Mechanical Engineering, 15(4), 873-884. https://doi.org/10.1016/j.acme.2015.07.002

Ebeling, C. E. (2000). An introduction to reliability and maintainability engineering. McGraw-Hill INDIA.

Gilchrist, W. (1993). Modelling failure modes and effects analysis. International Journal of Quality \& Reliability Management.

Helman, J. (2012). Analysis of the potentials of adapting elements of Lean methodology to the unstable conditions in the mining industry. AGH Journal of Mining and Geoengineering, 36(3), 151-157. DOI:10.7494/MINING.2012.36.3.151

Jansons, V., \& Jurenoks, V. (2012). Modelling the Behaviour of Stability of Production Systems in Economics. Economics \& Business, 22.

Kirjanów-Błażej, A., Jurdziak, L., Burduk, R., \& Błażej, R. (2019). Forecast of the remaining lifetime of steel cord conveyor belts based on regression methods in damage analysis identified by subsequent DiagBelt scans. Engineering Failure Analysis, 100, 119-126. https://doi.org/10.1016/j.engfailanal.2019.02.039

Koman, M., \& Laska, Z. (2014). Rozwiązania konstrukcyjne elementów systemu transportu taśmowego O/ZG Rudna, pozwalające na zmianę kierunku przesyłu urobku. Cuprum: Czasopismo Naukowo-Techniczne Górnictwa Rud.

Kuric, I., Císar, M., Tlach, V., Zajačko, I., Gál, T., \& Więcek, D. (2018, September). Technical diagnostics at the department of automation and production systems. In International Conference on Intelligent Systems in Production Engineering and Maintenance (pp. 474-484). Springer, Cham. https://doi.org/10.1007/978-3319-97490-3_46

Mahmood, K., Zidouri, A., \& Zerguine, A. (2008). Performance analysis of a RLS-based MLP-DFE in timeinvariant and time-varying channels. Digital Signal Processing, 18(3), 307-320. https://doi.org/10.1016/j.dsp.2007.04.006

O'Connor, P., \& Kleyner, A. (2012). Practical reliability engineering. John Wiley \& Sons.

Pačaiová, H.; Andrejiová, M.; Balažiková, M.; Tomašková, M.; Gazda, T.; Chomová, K.; Hijj, J.; Salaj, L. (2021). Methodology for Complex Efficiency Evaluation of Machinery Safety Measures in a Production Organization. Appl. Sci. 2021, 11, 453. https://doi.org/10.3390/app11010453

Pavlenko, I., Saga, M., Kuric, I., Kotliar, A., Basova, Y., Trojanowska, J., \& Ivanov, V. (2020). Parameter Identification of Cutting Forces in Crankshaft Grinding Using Artificial Neural Networks. Materials, 13(23), 5357. https://doi.org/10.3390/ma13235357

Pecháč, P., \& Sága, M. (2017). Memetic algorithm with normalized RBF ANN for approximation of objective function and secondary RBF ANN for error mapping. Procedia engineering, 177, 540-547. https://doi.org/10.1016/j.proeng.2017.02.258

Petrović, D. V., Tanasijević, M., Milić, V., Lilić, N., Stojadinović, S., \& Svrkota, I. (2014). Risk assessment model of mining equipment failure based on fuzzy logic. Expert Systems with Applications, 41(18), 8157-8164. https://doi.org/10.1016/j.eswa.2014.06.042

Pihnastyi, O., \& Khodusov, V. (2020, May). Neural model of conveyor type transport system. In CEUR Workshop Proceedings (Vol. 2608, pp. 804-818). https://ssrn.com/abstract=3642949

Procházka, P. P. (2014). Rock bursts due to gas explosion in deep mines based on hexagonal and boundary elements. Advances in Engineering Software, 72, 57-65. https://doi.org/10.1016/j.advengsoft.2013.06.013

Rosienkiewicz, M. (2012). Idea of adaptation value stream mapping method to the conditions of the mining industry. AGH Journal of Mining and Geoengineering, 36(3), 301-307. DOI:10.7494/MINING.2012.36.3.301

Sankar, N. R., \& Prabhu, B. S. (2001). Modified approach for prioritization of failures in a system failure mode and effects analysis. International Journal of Quality \& Reliability Management. https://doi.org/10.1108/02656710110383737

Sentyakov, K., Peterka, J., Smirnov, V., Božek, P. and Sviatskii, V. (2020). Modeling of Boring Mandrel Working Process with Vibration Damper. In Materials. Vol. 13, iss. 8 (2020), s.1-13. ISSN 1996-1944

Sharan, S. K. (2007). A finite element perturbation method for the prediction of rockburst. Computers \& Structures, 85(17-18), 1304-1309. https://doi.org/10.1016/j.compstruc.2006.08.084

Tao, R., \& Tam, C. M. (2012). System reliability optimization model for construction projects via system reliability theory. Automation in construction, 22, 340-347. https://doi.org/10.1016/j.autcon.2011.09.012 
Tillman, F. A., Hwang, C. L., \& Kuo, W. (1977). Optimization Techniques for System Reliability with RedundancyHA Review. IEEE Transactions on Reliability, 26(3), 148-155. DOI: 10.1109/TR.1977.5220100

Tlach, V., Císar, M., Kuric, I., \& Zajačko, I. (2017). Determination of the industrial robot positioning performance. In MATEC Web of Conferences (Vol. 137, p. 01004). EDP Sciences.https://doi.org/ 10.1051/matecconf/201713701004

Turisová, R.; Pačaiová, H.; Kotianová, Z.; Nagyová, A.; Hovanec, M.; Korba, P. (2021). Evaluation of eMaintenance Application Based on the New Version of the EFQM Model. Sustainability 2021, 13, 3682. https://doi.org/10.3390/su13073682

Wang, J., Yang, J. B., \& Sen, P. (1995). Safety analysis and synthesis using fuzzy sets and evidential reasoning. Reliability Engineering \& System Safety, 47(2), 103-118. https://doi.org/10.1016/0951-8320(94)00053-Q

Więcek, D., Burduk, A., \& Kuric, I. (2019). The use of ANN in improving efficiency and ensuring the stability of the copper ore mining process. Acta Montanistica Slovaca, 24(1).

Wirth, H., Kulczycka, J., Hausner, J., \& Koński, M. (2016). Corporate Social Responsibility: Communication about social and environmental disclosure by large and small copper mining companies. Resources Policy, 49, 53-60. https://doi.org/10.1016/i.resourpol.2016.04.007

Zajačko, I., Gál, T., Ságová, Z., Mateichyk, V., \& Wiecek, D. (2018). Application of artificial intelligence principles in mechanical engineering. In MATEC web of conferences (Vol. 244, p. 01027). EDP Sciences. https://doi.org/10.1051/matecconf/201824401027

Zhang, Z., \& Chu, X. (2011). Risk prioritization in failure mode and effects analysis under uncertainty. Expert Systems with applications, 38(1), 206-214. https://doi.org/10.1016/j.eswa.2010.06.046 